\section{Functional Carbon Nanoflakes with High Aspect Ratio by Pyrolysis of Cured Templates of Block Copolymer and Phenolic Resin}

Antti Soininen, ${ }^{\dagger}$ Sami Valkama, ${ }^{\dagger}$ Antti Nykänen, ${ }^{\dagger}$ Ari Laiho, ${ }^{\dagger}$ Harri Kosonen, ${ }^{\dagger}$ Raffaele Mezzenga, ${ }^{\dagger},{ }^{\circ}$ and Janne Ruokolainen $*, \uparrow$

Department of Engineering Physics and Mathematics and Center for New Materials, Helsinki University of Technology, P.O. Box 2200, FI 02015 TKK Espoo, Finland, Department of Physics and Fribourg Center for Nanomaterials, Ch. du. Musée 3, CH-1700 Fribourg, Switzerland, and Nestlé Research Center, Vers-Chez-les-Blancs, 1000, Lausanne 26, Switzerland

Selective separation of gases such as $\mathrm{O}_{2} / \mathrm{N}_{2}$ or $\mathrm{CO}_{2} / \mathrm{CH}_{4}$ through membranes is a rapidly growing field in industrial gas production. ${ }^{1}$ Additionally the oxygen separation process is central, for example, in packaging requirements for pharmaceutical, food, and cosmetics applications, where diffusion of oxygen has to be hindered. The majority of today's gas separation membranes are based on polymeric hollow-fiber modules. ${ }^{1}$ Efficient materials permitting good selectivity and high permeation to be achieved have been proposed, such as microporous zeolites or carbon based materials. ${ }^{2-7}$ Microporous carbon materials ${ }^{8,9}$ have uniform pore sizes of several angstroms and have particularly interesting gas separation properties. To limit their high processing cost and inherent brittleness, these materials are often combined with polymer matrices to yield polymeric membranes with efficient selective separation performance. ${ }^{10-14}$ Enhanced $\mathrm{O}_{2} / \mathrm{N}_{2}$ or $\mathrm{CO}_{2} / \mathrm{CH}_{4}$ selectivity has been achieved by using spherical microporous carbon particles with diameter from submicrometer to a few micrometers ${ }^{12}$ or using high aspect ratio planar flakes made of aluminophosphate. ${ }^{13}$ Recent efforts toward suitable design of carbon nano-

Helsinki University of Technology.

¥ Department of Physics and Fribourg Center for Nanomaterials.

$\S$ Nestlé Research Center.

(1) Baker, R. W. Ind. Eng. Chem. Res. 2002, 41 (6), 1393-1411.

(2) Jones, C. W.; Koros, W. J. Carbon 1994, 32 (8), 1419-1425.

(3) Fuertes, A. B.; Centeno, T. A. J. Membr. Sci. 1998, 144 (1-2), 105111.

(4) Linkov, V. M.; Sanderson, R. D.; Jacobs, E. P. J. Membr. Sci. 1994, 95 (1), 93-99.

(5) Shiflett, M. B.; Foley, H. C. Science 1999, 285 (5435), 1902-1905.

(6) Jia, M. D.; Peinemann, K. V.; Behling, R. D. J. Membr. Sci. 1993, 82 $(1-2), 15-26$.

(7) Jia, M. D.; Peinemann, K. V.; Behling, R. D. J. Membr. Sci. 1991, 57 $(2-3), 289-296$.

(8) Lee, J.; Kim, J.; Hyeon, T. Adv. Mater. 2006, 18 (16), 2073-2094.

(9) Lu, A. H.; Schuth, F. Adv. Mater. 2006, 18 (14), 1793-1805.

(10) Vu, D. Q.; Koros, W. J.; Miller, S. J. Ind. Eng. Chem. Res. 2002, 41 (3), 367-380.

(11) Koros, W. J.; Vu, D. Q.; Mahajan, R.; Miller, S. Gas Separations using Mixed Matrix Membranes. U.S. Patent No. 6,503,295, 2003.

(12) Vu, D. Q.; Koros, W. J.; Miller, S. J. J. Membr. Sci. 2003, 211 (2), $311-334$.

(13) Jeong, H. K.; Krych, W.; Ramanan, H.; Nair, S.; Marand, E.; Tsapatsis, M. Chem. Mater. 2004, 16 (20), 3838-3845.

(14) Zoppi, R. A.; das Neves, S.; Nunes, S. P. Polymer 2000, 41 (14), $5461-5470$. objects ${ }^{15-17}$ possibly serving as sieves have focused on the design of spherical ${ }^{15,16}$ and cylindrical ${ }^{17}$ structures and other mesoporous carbon matrix materials including gyroid structures. ${ }^{18-22}$ Yet, to obtain high gas permeation rates the thickness of the selective separation layer has to be very thin ${ }^{1}$ $(<0.5 \mu \mathrm{m})$ which makes of utmost importance the design of the shape and aspect ratio of zeolites, carbon, or ceramic molecular sieve materials. When using flakes, in particular, the planar shape of the sieves allows, in principle, aligning the flakes parallel to the membrane surface, enabling very thin membranes.

A general procedure to design ceramic nano-objects with tunable shape, which includes planar flakes, has been reported using polyisoprene-polyethyleneoxide block copolymer templates. ${ }^{23-25}$ Yet, no work has been reported up to date on carbon nanoflakes, which, as a result of their high selectivity, would have even larger relevance for polymer based membranes.

Here we report a strategy to design microporous carbon nanoflakes, by combining the self-assembly of block copolymer templates, selective swelling of a specific mesophase by phenolics low molecular weight compounds, and controlled chemical pyrolysis at moderate temperature. A schematic representation of the procedure followed is reported in Figure 1.

Low polydispersity index $(\mathrm{PI}=1.09)$ polystyrene-blockpoly(4-vinylpyridine) (PS-P4VP; number average total molecular weight, $M_{\mathrm{n}}=45600 \mathrm{~g} / \mathrm{mol}, 12 \% \mathrm{P} 4 \mathrm{VP}$ ) was selected as block copolymer template (Polymer Source, Inc.). This block copolymer alone formed P4VP spheres in a continuous PS matrix; see Supporting Information Figure S1. When mixed with phenolic resin (Vulkadur RB, Bayer, Ltd.) and hexamethylenetetramine (HMTA) as the curing agent (phenolic resin/HMTA ratio of 88:12) a selective swelling of the P4VP phase was achieved owing to hydrogen-bonding complexation between the phenolic and P4VP. By using a

(15) Kowalewski, T.; Tsarevsky, N. V.; Matyjaszewski, K. J. Am. Chem. Soc. 2002, 124 (36), 10632-10633.

(16) Tang, C. B.; Qi, K.; Wooley, K. L.; Matyjaszewski, K.; Kowalewski, T. Angew. Chem., Int. Ed. 2004, 43 (21), 2783-2787.

(17) Kruk, M.; Dufour, B.; Celer, E. B.; Kowalewski, T.; Jaroniec, M.; Matyjaszewski, K. Chem. Mater. 2006, 18 (6), 1417-1424.

(18) Lee, J.; Yoon, S.; Hyeon, T.; Oh, S. M.; Kim, K. B. Chem. Commun. 1999 (21), 2177-2178.

(19) Ryoo, R.; Joo, S. H.; Jun, S. J. Phys. Chem. B 1999, 103 (37), 77437746.

(20) Liu, R. L.; Shi, Y. F.; Wan, Y.; Meng, Y.; Zhang, F. Q.; Gu, D.; Chen, Z. X.; Tu, B.; Zhao, D. Y. J. Am. Chem. Soc. 2006, 128 (35), $11652-11662$

(21) Meng, Y.; Gu, D.; Zhang, F. Q.; Shi, Y. F.; Cheng, L.; Feng, D.; Wu, Z. X.; Chen, Z. X.; Wan, Y.; Stein, A.; Zhao, D. Y. Chem. Mater. 2006, 18 (18), 4447-4464.

(22) Yang, H. F.; Shi, Q. H.; Liu, X. Y.; Xie, S. H.; Jiang, D. C.; Zhang, F. Q.; Yu, C. Z.; Tu, B.; Zhao, D. Y. Chem. Commun. 2002 (23), $2842-2843$

(23) Ulrich, R.; Du Chesne, A.; Templin, M.; Wiesner, U. Adv. Mater. 1999, 11 (2), 141-146.

(24) Renker, S.; Mahajan, S.; Babski, D. T.; Schnell, I.; Jain, A.; Gutmann, J.; Zhang, Y. M.; Gruner, S. M.; Spiess, H. W.; Wiesner, U. Macromol. Chem. Phys. 2004, 205 (8), 1021-1030.

(25) Simon, P. F. W.; Ulrich, R.; Spiess, H. W.; Wiesner, U. Chem. Mater. 2001, 13 (10), 3464-3486. 
a)

b)
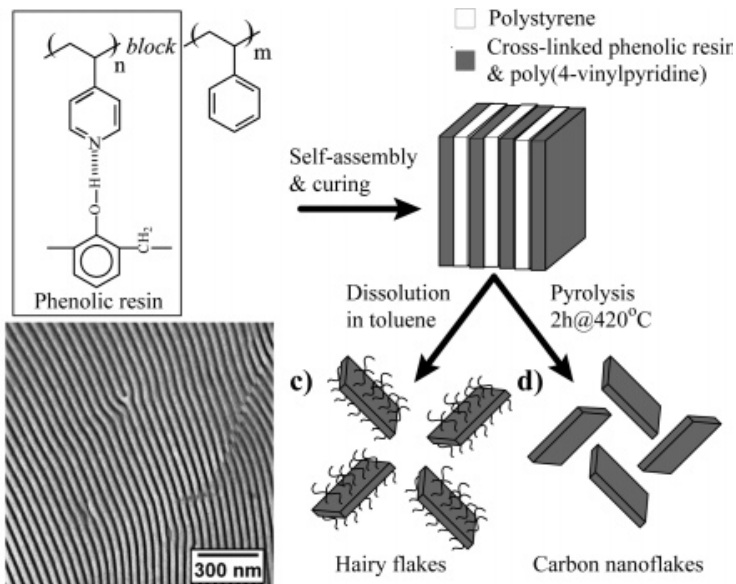

Figure 1. Schematics for the preparation of "hairy" flakes and pyrolyzed carbon flakes by using lamellar block copolymer template. (a) Phenolic resin, PS-P4VP block copolymer, and schematics of their mutual hydrogen bonding. (b) TEM micrograph showing a highly ordered lamellar structure after the cross-linking of the phenolic resin. (c) "Hairy" flakes can be obtained by dissolving the polystyrene lamellar phase in toluene. (d) Alternatively, during the selected pyrolysis conditions, block copolymer template is removed, leading to formation of carbon nanoflakes.

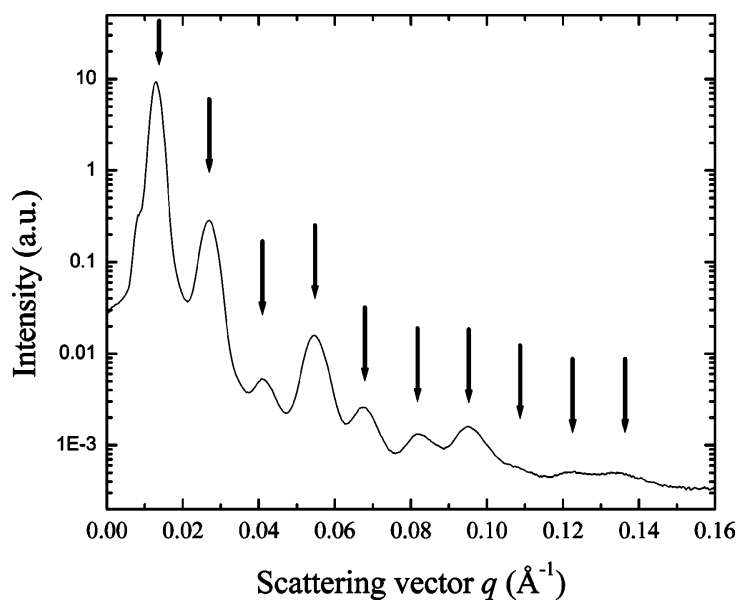

Figure 2. SAXS diffractogram showing long-range ordered lamellar phase with period of $46 \mathrm{~nm}$ in the cross-linked PS-P4VP block copolymer/phenolic resin blend.

total overall composition of $60 \mathrm{wt} \% \mathrm{PS}$ in the blend formed by PS-P4VP/HMTA/phenolic resin, a lamellar phase was finally obtained, as revealed by transmission eleectron microscopy (TEM) analysis (see Figure 1). Cross-linking of the P4VP domains with the phenolic/HMTA compounds was successively achieved by curing the blend at $190{ }^{\circ} \mathrm{C}$ for 2 h. Similar concepts using PS-P4VP template and phenolics formulations have been recently used to design micro- and mesoporous materials in bulk and thin films. ${ }^{26-28}$

Figure 2 shows a small-angle X-ray scattering (SAXS) diffractogram of the PS-P4VP/phenolic resin blend after the cross-linking. As many as 10 consecutive reflections, $q_{1}: q_{2}$ : $q_{3}: \ldots: q_{10}$ spaced as $1: 2: 3: \ldots: 10$ reveal the presence of a lamellar phase with very long range order. The first peak,

(26) Liang, C. D.; Hong, K. L.; Guiochon, G. A.; Mays, J. W.; Dai, S. Angew. Chem., Int. Ed. 2004, 43 (43), 5785-5789.

(27) Kosonen, H.; Valkama, S.; Nykanen, A.; Toivanen, M.; ten Brinke, G.; Ruokolainen, J.; Ikkala, O. Adv. Mater. 2006, 18 (2), 201-205.

(28) Valkama, S.; Nykänen, A.; Kosonen, H.; Ramani, R.; Tuomisto, F.; Engelhardt, P.; ten Brinke, G.; Ikkala, O.; Ruokolainen, J. Adv. Funct. Mater. 2007, 17 (2), 183-190

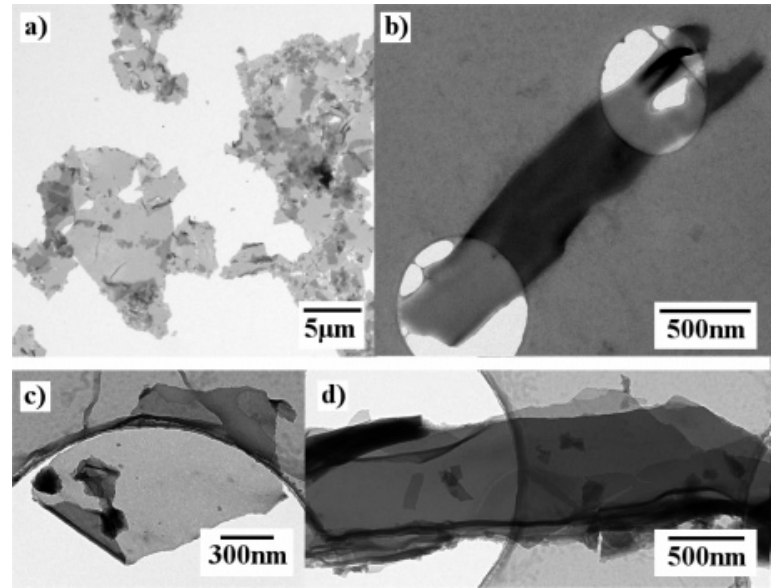

Figure 3. TEM images of nanoflakes as prepared by dispersing them onto holey carbon TEM grid from dilute solutions. (a) A low magnification image showing "hairy" nanoflakes obtained by the cross-linked but not pyrolyzed sample. (b) A higher magnification from the "hairy" nanoflake. The flake surfaces are covered with polystyrene brushes. (c) TEM micrograph showing carbon nanoflakes after the pyrolysis. (d) TEM image of an aggregate where a few flakes are stacked together.

centered at $q_{1}=0.136 \mathrm{~nm}^{-1}$, indicates an overall period of $46 \mathrm{~nm}$ for the lamellar organization. Starting from these lamellar structures two different types of nanoflake materials could be obtained on the basis of different post-processing routes.

In the first case "hairy" flakes of lateral size averaging from 1 to $10 \mu \mathrm{m}$ were obtained by dissolving the polystyrene lamellar phase in toluene. The flakes consisted of approximately 15-20 $\mathrm{nm}$ thick cross-linked P4VP-phenolic resin lamellae decorated on the surface by PS polymer brushes. The presence of a polymer brush on the surface of these flakes further enables dispersing the flakes within a polymeric matrix compatible with the polymer brush. By using different block copolymer templates one can thus access polymeric membranes on the basis of a vast class of homopolymers.

In the second case, carbon flakes with high aspect ratio were obtained by a controlled pyrolysis process. Cross-linked lamellar phases were maintained at $420{ }^{\circ} \mathrm{C}$ for $2 \mathrm{~h}$ in air. Previous work demonstrated that using these conditions both the PS lamellae and the P4VP polymer chains within the phenolic matrix are removed, leading to microporous carbon materials with an average micropore diameter of $5.4 \AA$, as measured by positron annihilation lifetime spectroscopy (PALS). ${ }^{28}$ Figure $3 \mathrm{a}$ shows the wide field TEM image of the hairy flakes obtained as described above and schematically illustrated in Figure 1c.

Figure 3b,c illustrates and compares at higher magnification TEM micrographs of "hairy" flakes and carbon flakes, respectively. In the case of Figure $3 c$, the edges of the carbon flakes appeared to be well defined and sharper than in the case of "hairy" flakes (Figure 3b). This is to be attributed to the presence of the PS brush decorating the surface of the "hairy" flakes, which diffuse the contrast in electron microscopy imaging. "Hairy" flakes could be easily dispersed in toluene solution whereas in the case of pyrolyzed carbon flakes ultrasonification was required to disperse them in organic solvents such as ethanol. Furthermore, in the case of carbon nanoflakes, a greater tendency to form small 
aggregates was observed compared to hairy flakes, as shown in Figure 3d, where a few-flakes aggregate is shown.

In conclusion we have presented a procedure to design carbon nanoflakes based on the self-assembly of block copolymer templates into long-range ordered lamellar morphologies, the selective swelling of one lamellar domain by phenolic resins, the cross-linking of this domain, and the controlled pyrolysis of the resulting material. The carbon flakes obtained with this procedure present a high aspect ratio (lateral size up to several micrometers and thickness of $\sim 20$ $\mathrm{nm}$ ), large surface area per unit volume, and microporosity, which is essential for selective separation applications. We anticipate that the procedure described here can potentially lead to microporous carbon materials for polymer separation membranes with enhanced and tunable properties.

Acknowledgment. This work was carried out in the Centre of Excellence of Finnish Academy ("Bio- and Nanopolymers Research Group", 77317) and supported by the European Commission-project COMPOSE NMP3-CT-2003-505633 and Academy of Finland. 